\title{
'Trust my doctor, trust my pancreas': trust as an emergent quality of social practice
}

\author{
Simon Cohn
}

\begin{abstract}
Background: Growing attention is being paid to the importance of trust, and its corollaries such as mistrust and distrust, in health service and the central place they have in assessments of quality of care. Although initially focussing on doctor-patient relationships, more recent literature has broadened its remit to include trust held in more abstract entities, such as organisations and institutions. There has consequently been growing interest to develop rigorous and universal measures of trust.
\end{abstract}

Methods: Drawing on illustrative ethnographic material from observational research in a UK diabetes clinic, this paper supports an approach that foregrounds social practice and resists conceiving trust as solely a psychological state that can be divorced from its context. Beyond exploring the less-than-conscious nature of trust, the interpretations attend to the extent to which trust practices are distributed across a range of actors.

Results: Data from clinical encounters reveal the extent to which matters of trust can emerge from the relationships between people, and sometimes people and things, as a result of a wide range of pragmatic concerns, and hence can usefully be conceived of as an extended property of a situation rather than a person. Trust is rarely explicitly articulated, but remains a subtle feature of experience that is frequently ineffable.

Conclusions: A practice approach highlights some of the problems with adopting a general psychological or intellectualist conception of trust. In particular, assuming it is a sufficiently stable internal state that can be stored or measured not only transforms a diffuse and often ephemeral quality into a durable thing, but ultimately presents it as a generic state that has meaning independent of the specific relationships and context that achieve it. Emphasising the context-specific nature of trust practices does not dismiss the potential of matters of trust, when they emerge, to be transposed to other contexts. But it does highlight how, on each occasion, trust as a relational quality is ways 'done' or 'achieved' anew.

Keywords: Trust, Diabetes, Practice theory, Quality

\section{Introduction}

Trust has become a ubiquitous word in relation to many contemporary concerns-from finance to health, from politics to the internet. Within the health context, it has increasingly been associated with discussions about the quality of care, since it potentially captures something of the non-technical, inherently interpersonal nature of healthcare delivery ${ }^{1}[1,2]$. In the UK, recent shocking, high-profile examples of neglect in hospital wards and care homes have been drawn on by many to illustrate some of the unintended consequences of setting institutional

Correspondence: Simon.cohn@lshtm.ac.uk

Reader in medical anthropology, Health Services Research and Policy,

London School of Hygiene and Tropical Medicine, 15-17 Tavistock Place,

London WC1H 9SH, UK targets and adopting financial incentives designed to increase the efficiency of the health service. Central to this claim is the argument that since people who seek help are, by definition, vulnerable, they have no choice but to rely on others for their care. As a result, both media reporting and official investigations have employed a bundle of terms, including compassion, empathy, care and trust, to contrast with organisational values associated with financial and bureaucratic rationalism (see for example, [3]). Trust has thereby come to represent one of the crucial dimensions of health service delivery said to potentially escape the domination of bureaucratic, administrative and market values [2]. 
In line with this, and in apparent contrast to the resilience of survey results that report doctors remain the most trusted profession [4], a number of authors have argued that instances of trust in health care settings are declining in reaction to the changing nature of the health service, paralleling an erosion of trust in society more generally $[5,6]$. At the centre of such propositions is the view that the intrinsically social nature of care is being subsumed by commercial and managerial forces, undermining the interpersonal foundations of clinical encounters and care itself [7]. In response, some have consequently advocated the introduction of 'intelligent' trustworthiness-that is, the careful and considered investment of appropriate trust - as a guiding principle to counter the impersonal systems of audit, accountability and the market [8]. The argument has proved to be powerful and persuasive, and often is reproduced uncritically [9]. Thus, whilst there may currently be limited evidence that levels of trust have a causal effect on clinical outcomes, there is nevertheless a growing assumption that it constitutes a crucial feature of care, and therefore should be protected and nurtured in order to improve people's experience of medical services and their overall health [10].

\section{Some limits of trust research}

The majority of classic writing assumes trust primarily relates to the dyad between a trustee and a trustor-in the health context, between the doctor and patientalthough in recent years, this scope has broadened to include more generalised kinds of trust; for example, in entities such as social structures, institutions and organisations $[11,12]$. Much of this work has concentrated on what trust means in an abstract sense, whether in terms of its definition, its distinctions with related terms, or by developing a set of analytical principles (see for example $[13,14])$. In this literature it is commonly said to be something we can 'have', that can be incrementally increased and built up, or decreased and even lost altogether [15]. It is also said that possessing trust serves as a means to navigate the relationship between expertise and authority, and is frequently conceptualised not only as the basis for co-operation between people, but as a resource to be drawn on [16]. It's not surprising, then, that many of these arguments draw on an underlying economic model in which trust is a precious form of capital that can be gained, invested, accumulated, given, undermined, earned, received, and so on. Some writers go further, and not only present it as an object of exchange and investment, but also the result of careful calculation, appraisal and management [17]. By reifying and generalising trust in this way, the associated terminology serves to support the idea it is a potentially measurable psychological entity [18], even though there is currently little agreement as to what dimensions to include, and hence no standard metric has been established [19].

However, as the psychologists Harvey et al. acknowledge [20], there is inevitably a difference between what people say about trust and what people actually do in practice (what they term 'stated' versus 'enacted' trust). A number of sociological studies investigating what is actually enacted in health contexts have consequently served to problematize the overtly mentalist approach of much trust research. Starting with the observation that it can be as much an affective state as a rational one, and that emotions can both guide and influence how trust evaluations are made [21], this work has, in combination, emphasised the complex negotiations that underlie interactions, and hence the plethora of situational factors likely to be significant. More specifically, ethnographic approaches not only reveal the subtle, pragmatic ways in which trust can surface [22] but also modes by which it is can be embodied (see for example [23]). Such work illustrates how conscious deliberations and evaluations of trust are often accompanied by other, less than conscious, processes. This general phenomenological approach highlights how objects and other non-human actors can shape the assumptions and interpretations actors make and that trust is actually a very fluid and varied entity (see for example [24, 25]). By doing so, this empirical work has led scholars to emphasise the contingent, contextual nature of trust [26], and that frequently there are other relevant actors beyond the classic dyad [27].

The renewed interest in care more generally, and in particular a relational approach that emphasises care as interaction rather than something that is simply bestowed on one person by another [28], also serves to illustrate the inherent ambiguity and ambivalence of health-related relationships. Brodwin [29] points out that because of this, care and coercion in health settings cannot easily be distinguished from each other, since the relationship between health carer and patient is invariably unequal and nonreciprocal. Thus, whilst trust might initially be associated with establishing symmetry or mutuality in a relationship, accounts also illustrate the ways in which sometimes trust can actually be produced by such imbalances. For example, some have noted how, in the health context especially, trust can sometimes be the only thing that an individual is left with when they have limited choice but remain dependent on others (see for example [30]). In such situations, both patients and professionals may try to preserve a sense of trust even when doing so is unjustified [31] and, further, that when they do so such attempts may become manipulative and surreptitious attempts to control the situation or the other party [32].

Nevertheless, whilst these primary accounts clearly demonstrate some of the ways in which deliberative 
evaluations of trust are accompanied by a wide range of other, non-conscious activities and effects, an implicit danger is that by continuing to adopt 'trust' as an abstract noun has the potential to reinforce the idea it can be separated from its context and that it consists of some universal properties independent of the situation within which it arises. Part of the problem is that this notion of trust commonly provides the basis on which it can be said to endure over time and in different contexts. Yet, as soon as it is rendered into such a generalised concept, discussion of trust necessarily has to become oversimplified and devoid of the specific details, histories and subjective standpoints that constitute its emergence in any particular instance. In other words, there remains a tension in the literature between, on the one hand, a strong emphasis on the situatedness of trust, and on the other, the use of a generic term that implies it is in some way an intrinsic, a priori, entity.

So how might one conduct an empirical study of trust in a health setting that resists presenting it as a bankable resource located inside the head or body, and instead presents it as a feature that is continually contingent on the features of specific contexts? By arguing that trust is not a psychological state or the result of deliberative evaluation, but rather something which only emerges from specific practices in particular situations shifts its conceptualisation from being an entity in and of itself, to being a quality potentially attributed by people to particular assemblages of people and things. Such a practicebased approach draws from diverse sources, including Pierce's pragmatism [33], Tarde's interactionist sociology [34] and Bourdieu's notion of habitus [35], to provide an account of human behaviour not through trying to ascertain its antecedents, but rather from examining the ways in which meaning is a consequence of human action [36]. Although variations of practice theory have circulated in the social sciences for a number of decades, there has been a growing interest in them over recent years. In part, this can be attributed to a rejection of the dominance of individually-focused models which attempt to describe behaviour as the linear consequence of a set of internal processes. This can all too easily support an ideology of responsibilisation, by which the imperative on individuals to manage and take control rapidly becomes an expectation that only they are responsible for their health status [37].

Practice theory, in contrast, adopts a somewhat counterintuitive approach, arguing that it is people's actions in the world as they connect and co-opt other people and things which create meaning [38]. Rather than reproduce the mentalists' distinction between what is conscious and what is automatic, a general commitment to embodied disposition and the interaction of 'background' [39] is used to highlight that, although we may not be aware of such processes, they are often comprise of very rich and creative processes. Initially this emphasis on how things are achieved or constructed 'in the present' may appear to negate the fact that trust has an enduring nature. After all, from the more usual perspective, trust is conceived of in terms of the influence it can have on how people access health care services or respond to them in the future; as such, it precedes in some form or other a particular event, such as choosing to take medication or follow a doctor's advice. But a commitment to interrogating what gets done and said in specific social situations implies that what might be said to 'travel' from one context to another is not 'trust' per se, but rather the range of sociocultural and material resources that have the potential to influence its emergence in a new setting through further practices.

\section{Diabetes and trusting relationships}

Drawing on observations in a UK diabetes clinic, the remainder of this paper will use excerpts to illustrate ways in which trust arises during everyday exchanges and activities between doctors and patients. Instead of basing interpretations primarily on people's reflections, attention is placed on the very specific circumstances of practice, including whatever material elements might play an integral role, since all these exert very real influence on shaping how an event is ultimately constructed or 'achieved'. In order to illustrate the themes introducedthat matters of trust are emergent, always contingent on multiple factors, and remain inherently ambivalent-I draw on instances when matters of trust appear to be foregrounded even if this is not articulated by actors themselves.

The idea of 'self-management' has become an increasingly common feature in the care of chronic conditions such as diabetes. It could be said to be derived from two distinct forces: the shift from paternalistic to patientcentred care, and acknowledgement that on-going treatment strategies now require continual attentiveness and adjustment. Accompanying terms such as empowerment and concordance, and the proliferation of so-called shared-decision making tools, the drive to encourage patients to monitor, record and alter their medication, diet and exercise is broadly conceptualised in terms of mimicking the homeostatic feedback that the body lacks in order to achieve biochemical stability. Accompanied by the rise of electronic devices to measure glucose levels, and insulin pens and pumps to adjust different kinds of insulin to provide either a basal or immediate response, patients are being increasingly encouraged to reflect and act autonomously on their metabolism 'in real time'.

Some commentators have been sceptical that an emphasis on promoting autonomy is in any way emancipating, and have commented that there is an increasing expectation that the idea of the patient as an 'active' 
subject who takes on primary responsibility for their care is merely an extension of disciplinary surveillance [40]. However, from another perspective it is not simply that the person with diabetes now has more things to do, but rather the patterning of who is responsible for doing those things, and when they are expected to be done, is shifting. In order to be able to manage their diabetes daily they must still use and rely upon a wide range of things and other people, just as they had done previously; but new configurations based on selfmanagement refashion the nature of those relationships. In order to try and achieve some kind of blood glucose stability given this new distribution, many different associations not only need to be established and maintained, but need to be trusted.

My starting point, therefore, is adopt the idea of practices in order to concentrate on the details that relate to how matters of trust emerge and are enacted in a diabetes clinic. Using ethnographic vignettes to illustrate some of the breadth of trust practices, the following results serve to exemplify some of the apparently incongruous situations and the multiplicity of actors which fall within their broad scope. These examples are selected precisely because they may well be missed using methods that assume trust is a stable entity, such as a questionnaire prompt or formal interview. Ultimately, this paper presents trust as the degree to which the sense of stability and predictability emerges from a set of relationships between people, physical objects and the material environment, and hence how a quality attributed to such practices may determine, or restrict, opportunities for repetition in the future.

\section{Results and discussion}

The findings below are derived from analysis that focused on identifying occasions when matters of trust come to the fore but are not necessarily made explicit. Although selective, the data are drawn upon to propose that trust, and associated terms such as mistrust, can be conceived of as qualities of the relationship between actors rather than things in themselves [41]. Whilst this necessarily implies trust is inherently subjective and situated, it opposes locating it either solely 'in the head' or as a feature of the external world. Rather, the data presents accounts of how people work to make sense of, and experience, their own position within a set of relationships, and how in this process particular actions can emerge as ones that convey trust as a quality of those connections.

\section{Connecting bodies and people}

Some people diagnosed with diabetes don't seem to ever find a way to accept this new status, and establish a selfidentity that accommodates, rather than resists, the condition. It is as though they are adrift, uncontained, and resolutely contest the idea of having to address the condition on their own. This was the case for Mary. She has Type I diabetes, but her mother has Type II. They invariably come to the clinic together, although of course are not seen together by a doctor. Nevertheless, the dynamic of mother and daughter is very strong, and shapes the consultations they both have. The relationship between them is undoubtedly complex; the father left the family almost a decade ago. The daughter has had poor blood glucose control for many years now-probably since she was diagnosed as a child. Although not yet diagnosed with a psychiatric condition, it is likely that she will soon also be referred for psychological help. Meanwhile, her eyesight is deteriorating due to retinopathy, and she has started to have ketoacidosis attacks and be admitted on and off as an emergency inpatient. The consultant wants the daughter to take control, to 'own' the condition, and to stop what the doctor called her 'reckless behaviour'. Regular selfmonitoring and insulin adjustments would hopefully lead to greater coherence and integration into her everyday life; he is concerned that she might find herself caught in a never-ending cycle of very poor control and hospital admission. So he asks her:

Dr: What do you think the best thing to do might be?

Mary: Get my mother to leave me alone

Dr: But surely she is trying to help you... make sure you are ok, and control your diabetes?

Mary: I just think she should worry about her own diabetes, not mine. I'm ok. I know what I'm doing.

Dr: Do you? I mean, your HbA1c results are not good, Mary.

Mary: No, well. That's not the whole story, is it? There are more things to worry about than a one-off blood test.

Mary's words not only suggest she is caught in loops of uncertainly and distrust in relation to the health service and health care professionals, but that she is also questioning whether or not she can trust her mother. On the one hand, she responds to the consultant's first question by rebuffing the influence of her mother's apparent stifling concern. Yet almost immediately afterwards, Mary rejects the idea that her diabetes management can be assessed by a single blood measurement (the HbAlc result), since to do so would disregard the 'whole story' of her distress and that the illness is constituted by multiple relationships. As the exchange continues, it is clear that for Mary the 
notion of being 'out of balance', as she put it, is a diverse and wide-ranging state rather than one that can be attributed solely to her glucose levels, and that what she really seeks is a much broader feeling of things being settled, in which she, and her own body, are positioned. From her perspective the condition arises not merely from her internal physiology, but from an entangled network of diverse elements which all affect her sense of constancy and balance-and it is potentially all of these that can play a role in her sense of stability.

This then, invites one to rethink the notion of selfmanagement of diabetes-that in practice this means management of a wide variety of relationships. In the context of diabetes, practices of trust consequently relate to the need to establish a feeling of stability, rather than empirical evidence of it, across many different kinds of relationships in order to counter feelings of vulnerability or uncertainty. In this way, trust describes a relational quality that emerges from interaction. And while it is always made, or unmade, in the present, its effect is to appear not only as something that will endure to potentially shape future interactions, but just as significantly can be extended backwards, to refashion how past experiences are recalled and brought into association with the present.

\section{The effects of not saying}

In real-life clinical settings, it is often the apparently superfluous or ritualised elements of social interaction that are most relevant, since they function to establish a level of sociality that is independent of the specific medical content that may be imparted. As well as what may be said, it can also be what is not said that engenders a sense of trust. For example in the following exchange between a consultant and John, a 49 year old patient with Type II diabetes, the utterances from both parties could be said to be quite scripted:

Dr: So, tell me how things have been going. How has the diabetes been?

John: Fine, ok I suppose.

Dr: Good... I mean, anything been bothering you... Any problems?

John: ....No.

Dr: No. Well. Good. I mean, are you sure?

John: Yes.

Dr: Oh, OK then. Good.

[PAUSE]
But amidst this ostensibly mundane excerpt a lot is implicitly going on. The doctor is trying to gently encourage John not only to feel at ease, but to be frank and honest with him, whilst the patient is reluctant to make himself more defenceless than he already feels. As a result, the doctor, having asked a second time, decides not to press any further. Following this short exchange there is a brief pause, which serves to confirm the significance of something which was not said. The short period of silence establishes a shared secret between the two, since neither decides to instigate anything further. Instead, the conversation turns to the more technical matter of insulin dosage. But by each allowing the pause in conversation, a kind of acknowledgment of the other person's position is intimated, and a sense of mutual trust based on difference, rather similarity, is established.

If prompted to talk explicitly about trust, respondents like John seldom offered an immediate summative response, but instead recounted one or two particular incidents or interactions from which they then made some sort of evaluation, to themselves as well as myself as the researcher. So when asked in what ways they trusted (or did not trust) the doctor that they had just talked to, patients would often focus on particular things that were said, or actions that were taken, as indicative of a more general and distributed feeling of trust. In the following excerpt, for example, a female patient who had just met a new consultant for the first time, draws on some material objects that she felt were instrumental in being able to establish, retrospectively, the nature of the relationship she had with the doctor:

Thinking about it now, I didn't trust him at the beginning. I looked over on the desk, and instead of my notes, which usually consist of a really thick pile of papers from all the years I have been going, there was just a small brown A4 folder... with maybe just a couple of sheets of paper inside... I think that being so surprised by that folder really affected how I spoke to him [the doctor], and perhaps even what I said about my diabetes.

The lack of extensive notes is contrasted with the usual bundle of paperwork-and in so doing calls attention to the regular expectations and network of ways of doing things, and an interruption to a sense of familiarity and continuity. Clearly, for this patient, an established opinion on whether she felt her relationship with the doctor was a trusting one or not did not really exist beforehand. Only following a prompt during the interview did she actively reflect upon things; while recounting the apparently minimal paperwork the presence of the thin folder itself intervened in her assessment of the nature of her relationship with doctor. The more general 
point is therefore that trust is commonly an aspect of social life that is not articulated, whether to others or even people themselves. In order to talk about trust at all, assessments are made of particular events that, at the time, may not have felt noteworthy. Describing what was done or not done, as well as what was thought or said, is in parallel a process of specifying the quality of the connections that comprise the specific practices.

\section{Actions of deception}

Perhaps surprisingly, one of the range of actions that falls within trust practices but would be excluded from a study that adopted a more objectivist approach is that of deception. Dishonesty is quite a common feature of encounters at the clinic. From the medical professionals' perspective, because the underlying imperative is to try and ensure the patients' relationships with the clinic and staff members are durable, they will often tolerate such acts because there are there are bigger things to worry about'. Meanwhile, since patients often feel that it is not their diabetes that is being assessed but they themselves are being morally judged, they adopt various defence strategies.

For example, the task of self-monitoring is often one that many patients do not do as regularly as they are advised to. Nevertheless, they often feel it is important to try and please their doctors and nurses, and as a result, sometimes fill in the blood glucose diaries just before an appointment. In fact, some become quite sophisticated at this-even (so they told me) allowing tiny drops of blood mark the paper to further suggest the authenticity of the record. On one occasion, I asked Sue, a patient with Type II diabetes who now uses insulin after being on oral medication for many years, directly about this:

Me: But surely, isn't the diary in the end just to help you, to help you see whether your medication is keeping your glucose levels stable and low?

Sue: I suppose. Yes. But I have my own ways to do that. The diary thing, well, they asked me to do it, so I don't want to disappoint them...

Anyway, I naturally didn't say anything to anyone about what she had said, and her trick of using a blue pen and a black pen alternately to fill out the diary. On a separate occasion, however, a nurse specialist at the same clinic spontaneously told me that she, and everyone else working in a diabetes clinic, often did not believe a patient really had completed the dairy legitimately. She told me 'they weren't so easily duped' and that 'you cannot trust those'-perhaps deliberately leaving the statement ambiguous as to whether she was referring to the diaries of the patients. The nurse went on to tell me that invariably there would be specific clues- the form of the writing, the measurements themselves, and so on. So I asked her why she never challenged patients when suspected this. She replied:

That would just be too damaging. We carefully build up relationships with patients. We don't preach at them, we go at their pace, we build up trust... And anyway, the diary is meant to be for them. We use HBA1c to assess glucose levels-it's far more accurate. And objective.

The diary not only serves as a means to produce and maintain the fiction that self-monitoring is being conducted regularly, but is drawn upon by both the patient and the health professional to maintain a sense of commonality, even if both sides know it to be fake: for either of them to reveal this 'secret' would be too destructive. In this way, a broader sense of trust emerges from the specific configuration of deception and mistrust.

Accounts such as this not only illustrate how the scope of trust practices must include a range of related terms, because they all in different ways infer what form of trust emerges from the interactions between people and things, but also that apparently contradictory practices can, from different perspectives, engender (or undermine) the emergence of trust. Thus, beyond acknowledging that trust cannot be conceptualised as an object or resource because it is inherently a relational quality that always emerges from very particular configurations, on any occasion new elements might be foregrounded, while others recede. As a result, conceptualising the quality of trust as being constant or fixed not only ignores the possibility that at any time it can radically alter, but that this experience of precariousness is itself one that engenders trust as a stabilising feature.

\section{Threats of betrayal}

Jane had thought that she was, in her words, 'a good diabetic patient'. By that, she meant that she monitored herself regularly, and had a sufficient understanding of the biomedical model to allow her to dial up and alter different doses of the fasting acting and slow acting types of insulin she was on. However, after an HbAlc test, which give average blood glucose levels over the previous three months or so, it transpired that her control was not nearly as good as she had thought. At first she doubted the HbA1c figure, but her doctor emphatically told her it was reliable and now the standard way they measured glucose control. So if Jane wanted to trust her doctor, she also had to trust this test result. Jane paused for a short while, and then suggested that perhaps it was her electronic glucose meter that hadn't been working properly, and that although she had done everything 'correctly', it may have consistently given false 
readings. Her doctor was clearly not convinced; he conceded it was 'possible', but he said this in such a way that it was clear he really didn't accept it as a reasonable explanation. Jane sensed this, and that the doctor was starting to get a little frustrated. So she tried one more time to protect her status as being someone who was good at self-management not only to the doctor, but herself also, and began to ask if one or both of the insulin types could somehow be contaminated, or of an inferior strength. But her voice trailed off as the doctor started to shift in his chair, now a little agitated that Jane was not accepting, from his perspective, the reality of the situation. Finally, Jane said the following, while she gently rested her hand on her midriff:

Ok. Well, I still don't understand it. I did everything that I was meant to. I managed really well, as you know. But perhaps it's something to do with my pancreas or something. Maybe my body is, you know, misbehaving or something. Maybe it's my pancreas...

In the course of the exchange and Jane's concluding speculation, the fact that the puzzling test result was inescapably nestled in a number of other trusting relationships that she did not want to have undermined, forced Jane to work through an account in which she could preserve what was most important. As different possibilities are brought to the fore they are experienced as potentially competing with others; attributing trust to one relationship required the severing of trusting relationships in others. The exchange itself was a delicate choreography, as new possible actors were introduced by the patient only to be cautiously dismissed by the doctor. Finally, blaming her own body may well have been a somewhat linguistic flourish-but it nevertheless served as a way to protect the trust Jane valued elsewhere. For her, living with diabetes is far from being simply about her pancreas, and that ultimately losing trust in her body became a strategy to preserve a sense of trust in other things that she experienced as even more fundamental to her condition.

This last ethnographic example illustrates the fact that trust practices can enlist a wide range of entities-people, institutions, material objects and even one's own bodyand that one cannot assume which entities are necessarily more significant in a particular configuration than others. Trust is not contained simply in the person, but arises from the specific distribution of all these things. Further, the potential combination of such diverse elements is experienced by people such as Jane as a fluid landscape that can be creatively drawn on to make meaning, rather than existing as a stratified hierarchy which dictates some kind of logic. As a result, any sense of trust is always ephemeral, since it is contingent on the particular elements brought to the fore.

\section{Conclusions}

In this paper I have suggested that we resist conceiving trust as an object or a resource. Although in much of the literature trust is frequently presented as a counter position to the influence of financial pressures in the health service, conceiving it as a form of capital that can be drawn on, invested and traded, far from representing an alternative to rational bureaucracy can reproduce and reinforce the same market principles and forces. An alternative approach, based on the increasing interest in more ethnographic accounts of trust, presents it as an inherently emergent quality of interacting features that arises during specific practices. To acknowledge its complex and often multivalent nature, and the very indeterminacy and instability which fosters it, means that trust is always contingent on a particular context and specific associations. Arguing that trust is a subjective quality of a set of relationships reiterates the point made by others that it is not simply associated with a patient trusting the health professional, or vice versa, but should be broadened to include all manner of relationships, including trusting oneself, one's body, the health service, and other significant people. All these forms coalesce around a person at times when they feel vulnerable and try to make sense of their situation by locating themselves in a network of relationships that might sense of stability.

Beyond highlighting how trust can be both a conscious evaluation yet is also unconsciously affected by a wide range of factors, I have suggested that to do so nevertheless can maintain a mentalist or egocentric conception. A practice orientation is a way to conceptualise the more distributed nature of situated actions from which individuals may gain a sense of trust. In this way, I have tried to argue that the exceptional status of the person as the repository of trust should be challenged by attending to the material elements, such as a glucose monitoring diary, or even a diseased part of the body, that can be just as active in its emergence. The consequence of this approach means that the identification of agency, which tends to be implied in discussions about trust being gained or lost, for example, must also be distributed across the heterogeneous assemblage. Taking a cue from Montelius and Giritlis-Nygrens' work on 'doing risk' [42], it is therefore not simply a matter of a person 'doing' trust work or 'accomplishing' it, but rather that a person may come to identify certain configurations in which they find themselves as ones that engender a sense of trust. Uncertainty over the extent to which they are the ones who 'do' the trusting is precisely one of its features-a person cannot simply 'decide' to trust or not. A related point is not just that trust can be thought about as a quality that emerges from a situated context, but that it cannot be rigorously demarcated from other associated qualities-such as mistrust and distrust. Not 
only does this reflect how attributing the quality of trust is invariably nebulous and multimodal but, as the examples have illustrated, what may be identified as trust frequently occurs alongside mistrust and distrust, rather than at the exclusion of them [43, 44].

In the specific context of diabetes care, rather than thinking about diabetes as a singular disease entity, the observations within a clinic suggest that one can instead think about diabetes practice as a collection of many successive occasions on which people (patients, doctors, nurses, relatives, friends, etc.) and objects (monitors, syringes, pumps, etc.) are brought together to regulate a blood glucose level (because to not have diabetes means that these different actors are not brought together). A patient's ongoing engagement with diabetes, whilst described as selfmanagement, in reality necessitates frequent arrangements with many different objects and people-and includes many more than those normally foregrounded at the clinic. Highlighting these relationships above individual decisionmaking extends the notion of management of metabolism and homeostasis, which are generally conceived of as internal and physiological, to include all the relationships of actions, reactions and feedback mechanisms that potentially constitute living with diabetes. It is through this more expansive approach that a revised concept of trust is pertinent-as a quality that may be attributed to varied relationships that are temporarily established that might suggest, or promise, a level of constancy and security.

The examples of diabetes management clearly illustrate this. The problem for both patients and professions is that rather than being in control of many of these elements, there is always an inherent sense of uncertainty. The clinical expectation is that patients should 'own' their condition and work to achieve physiological control over time by monitoring their blood glucose, adjusting their medication, and being vigilant about their diet and exercise. Yet from the patients' point of view, it makes little sense to try and achieve this kind of biological stability independent from all the other kinds of relationships that they experience as pertinent. The homeostatic quest is consequently not simply about levels of sugar or insulin, but the multiple connections and feedback relationships that constitute the flow of everyday life. As a result, far more diverse practices are drawn on as ones relevant to their condition, and therefore might be considered stable or not. However, trust as a quality of those relationships is never established uniformly across this diverse range of factors, or at every scale. As people draw on certain elements in order to establish a sense of trust, this frequently comes at the cost of destabilizing other relationships.

Given the increasing importance of discussions about trust in health service delivery and the quality of care, my purpose has not simply been to deconstruct its usual conception, or purely emphasise its dynamic and complex nature. Rather, it has been to point out that by attending to the specific details of ethnographic description, trust as a stable, quantifiable and generalised resource rapidly dissolves-not through intellectual analysis, but because in everyday life it simply does not exist as such an entity. This suggests that chasing a singular, generalisable concept or measure not only provides a restricted representation, but that in doing so we may actually exclude the specific features that characterises its role and potential in health settings. This is because the very process of making it known in this way separates it from those more dynamic, context-specific, and contingent features which make relationships with people, things and our bodies active and meaningful. In contrast, I have suggested one can talk about trust as a quality that on occasions is attributed by people to particular assemblages of persons and things, and that in the case of diabetes management this quality equates to a general sense of stability. But within this, a new issue arises; as a person evaluates specific practices they also come to reflect upon their own place within them, and the nature of the ties they have with other people and things. In this way, trust is neither an object nor a subjective feeling, but rather a quality experienced by persons as they reflect upon their own place in multiple networks of relations.

\section{Methods}

This research is based on extensive ethnographic observations of a diabetes clinic in a large NHS hospital in England, UK conducted as part of a larger multidisciplinary study during 2012-13. The data is drawn from the study "East Cambs \& Fenland Diabetes Integrated Care Evaluation", which gained NHS Health Research Authority ethical approval (reference: 11/EE/0148 ). Consent was obtained from all participants and health care professionals. All names are pseudonyms. Consultations and interviews were audiorecorded and transcribed and imported into NVivo 10 along with fieldnote texts. After a general inductive analysis using techniques from grounded theory to identify and develop themes [45], examples were chosen that best illustrated the general topics identified.

One of the features of ethnographic research is that it does not claim to be directly reproducible, because data is understood to be co-created by those being researched and the researcher themselves [46]. In addition, attending to the specific material aspects of a social situation as potentially equally significant further means that individual vignettes must be recognised as unique occurrences, and cannot be readily generalisable. However, in response to claims that the data is thereby purely anecdotal, this kind of research gains its relevance and from the abductive theoretical claims and arguments developed, rather than empirical details presented. In other words, although the paper emphasises that specific utterances and scenarios are unique, and although analysis is acknowledged to be interpretative and hence open to 
claims of subjective bias, the issues underlying them are consequently proposed as being applicable to other instances, involving other people in other settings.

These methodological issues therefore directly correspond to the argument presented in the paper; engaging with any idea of 'quality' in health must, ultimately, be concerned with thinking through how best to capture the contingent aspects of care that resist or escape containment, since to not try to do so would be to ignore their more radical and subversive potential to interfere with the more established categories that tend to represent what we take to be 'social reality'.

\section{Endnote}

${ }^{1}$ This paper is based on a talk presented at The Many Meanings of 'Quality' in Healthcare, Cumberland Lodge, UK, 4 June 2013.

\section{Competing interests}

The author declares that they have no competing interests. Although the author did not receive direct funding, the study from which this paper is derived was funded by an NIHR Research for Patient Benefit grant (PBPG080817303).

\begin{abstract}
Acknowledgements
I am grateful to the patients and staff who generously allowed me to observe and talk to them in the course of this research. I wish to also thank the two anonymous reviewers, who provided an unprecedented degree of insightful feedback and useful expert commentary in early drafts of this paper. Finally, I am indebted to the organisers of the event The Many Meanings of 'Quality' in Healthcare, held at Cumberland Lodge, UK, 4 June 2013 at which I presented an early version of this work.
\end{abstract}

Received: 14 August 2014 Accepted: 25 May 2015

Published online: 11 June 2015

\section{References}

1. Thom DH, Kravitz RL, Bell RA, Krupat E, Azari R. Patient trust in the physician: relationship to patient requests. Fam Pract. 2002;19:476-83.

2. Gille F, Smith S, Mays N. Why public trust in health care systems matters and deserves greater research attention. J Health Serv Res Policy. 2015;20(1):62-4.

3. Francis R. Report of the Mid Staffordshire NHS Foundation Trust Public Inquiry. London: The Stationery Office; 2013.

4. Veracity Index: Trust [https://www.ipsos-mori.com/Assets/Docs/Polls/ Feb2013_Trust_Topline.PDF]

5. Mechanic D. Changing medical organization and the erosion of trust. Milbank Q. 1996;74:171-89.

6. Rowe R, Calnan M. Trust relations in health care-the new agenda. Eur J Public Health. 2006;16:4-6.

7. Taylor-Gooby P. Markets and Motives Trust and Egoism in Welfare Markets Markets and Motives Trust and Egoism in Welfare Markets. J Soc Policy. 1999;28:97-114.

8. O'Neill O. Autonomy and Trust in Bioethics. Cambridge: Cambridge University Press; 2002.

9. Armstrong D. The myth of concordance: response to Stevenson and Scambler. Health (London). 2005;9:23-7.

10. Brown PR. Trusting in the New NHS: instrumental versus communicative action. Sociol Health IIIn. 2008;30:349-63.

11. Calnan MW, Sanford E. Public trust in health care: the system or the doctor? Qual Saf Health Care. 2004;13:92-7.

12. Gilson L. Trust and the development of health care as a social institution. Soc Sci Med. 2003;56:1453-68.

13. Meyer S, Ward PR. Reworking the sociology of trust: making a semantic distinction between trust and dependence. The Future of Sociology, Proceedings of the Australian Sociological Association conference. 2009. p. 1-16. Available at www.tasa.org.au/conferences/conferencepapers09/ appliedsociology.htm.
14. Lewis JD, Weigert A, Dame UN, Lewis D. Trust as a Social Reality. Soc Forces. 1985:63:967-85.

15. Hardin R. The Street-Level Epistemology of Trust. Politics \& Society. 1993:21:505-29.

16. Luhmann N. Familiarity, Confidence, Trust: Problems and Alternatives. In: Gambetta D, editor. Trust: Making and Breaking Cooperative Relations. Oxford: Oxford University Press; 2000.

17. Newton K. Trust, Social Capital, Civil Society, and Demoncracy. Int Polit Sci Rev. 2001;22:201-14.

18. Thom DH, Hall MA, Pawlson LG. Measuring Patients' Trust In Physicians When Assessing Quality Of Care. Health Aff. 2004;23:124-32.

19. Hall M, Camacho F, Dugan E, Balkrishnan R. Trust in the medical profession: conceptual and measurement issues. Health Serv Res. 2002;37(5):1419-39.

20. Harvey N, Twyman MHC. Determinants of trust in advice: Studies of the effectiveness of risk communication. Int J Psychol. 2008;43:198.

21. Baier A. Trust and Antitrust Ethics. 1986;96:231-60.

22. Skirbekk $H$, Middelthon $A-L, H j o r t d a h l ~ P$, Finset A. Mandates of trust in the doctor-patient relationship. Qual Health Res. 2011;21:1182-90.

23. Brown PR, Alaszewski A, Swift T, Nordin A. Actions speak louder than words: the embodiment of trust by healthcare professionals in gynae-oncology. Soc of Health IIIness. 2011;33(2):280-95.

24. Frederiksen M. Relational trust: Outline of a Bourdieusian theory of interpersonal trust. J Trust Res. 2014;4:167-92.

25. Brown P. The phenomenology of trust: A Schutzian analysis of the social construction of knowledge by gynae-oncology patients. Heal Risk Soc. 2009:11:391-407.

26. Meyer SB, Ward P. Differentiating between trust and dependence of patients with coronary heart disease: Furthering the sociology of trust. Heal Risk Soc. 2013;15:271-93.

27. Khodyakov D. Trust as a Process: A Three-Dimensional Approach. Sociology. 2007:41:115-32.

28. Noddings N. Caring: A Feminine Approach to Ethics and Moral Education. Berkeley: University of California Press; 1984.

29. Brodwin P. Everyday Ethics: Voices from the Front Line of Community Psychiatry. Berkley: University of California Press; 2013

30. Barbalet J. A characterization of trust, and its consequences. Theory Soc. 2009:38(4):367-82

31. Solbjør M. "You have to have trust in those pictures": a perspective on women's experiences of mammography screening. In: Brownlie J, Greene A, Howson A, editors. Researching Trust and Health. Oxon: Routledge; 2008.

32. Calnan M \& Rowe R. Trust matters in health care. McGraw-Hill International; 2008.

33. Peirce CS. How To Make Our Ideas Clear. In: Houser N \& Kloesel C, editors. The Essential Peirce Vol 1; 1992:124-141.

34. Candea M, editor. The Social after Gabriel Tarde: Debates and Assessments. London: Routledge; 2010.

35. Bourdieu P. The Logic of Practice. Stanford: Stanford University Press; 1990

36. Rouse J. Practice theory. In: Gabbay DM, Thagard P, Woods J, editors. Handbook of the Philosophy of Science, 15. 2006. p. 500-40.

37. Burchell G. Liberal government and techniques of the self. Econ Soc. 1993:22(3):267-82

38. Reckwitz A. Toward a Theory of Social Practices: A Development in Culturalist Theorizing. Eur J Soc Theory. 2002:5:243-63.

39. Taylor C. To Follow a Rule. In: Philosophical Arguments. Cambridge, MA: Harvard University Press; 1995. p. 165-80.

40. Lupton D. Risk. 2nd ed. Oxon \& New York: Routledge; 2013.

41. Deleuze G. Lecture transcripts on Spinoza's concept of affect [http:// www.webdeleuze.com/php/sommaire.html]

42. Montelius E, Giritli-Nygren K. "Doing" risk, "doing" difference: towards an understanding of the intersections of risk, morality and taste. Heal Risk Soc. 2014;16:431-43.

43. Haddow G, Cunningham-Burley S. Tokens of Trust or Token Trust? The case of Population Genetic Data Collections. In: Greene A, Brownlie J, Howson A, editors. Trust, Health and IIIness. London: Routledge; 2008.

44. Brown P, Calnan M. The risks of managing uncertainty: The limitations of governance and choice, and the potential for trust. Soc Policy Soc. 2010;9(01):13-24.

45. Charmaz K. Constructing Grounded Theory: A Practical Guide Through Qualitative Analysis. Thousand Oaks, CA: Sage Publications; 2000.

46. Gubrium JF, Holstein JA. Narrative practice and the coherence of personal stories. Sociol Q. 1998:39:163-87. 